\title{
ОФТАЛЬМОЛОГИЧЕСКИЕ АСПЕКТЫ СИНДРОМА "ПУСТОГО" ТУРЕЦКОГО СЕДЛА
}

\author{
*С.К.Гусейнова ${ }^{1}$, Х.К. Дуньямалиев ${ }^{2}$ \\ ${ }^{1}$ Национальный Центр офтальмологии им. академика 3. Алиевой, Баку \\ ${ }^{2}$ Национальный Центр онкологии, Баку
}

Ключевые слова: "пустое" турецкое седло, внутричерепная гипертензия, зрительные нарушения.

$\Pi$ роблема "пустого" турецкого седла является одной из малоизученных, но важных проблем нейроофтальмологии, неврологии и эндокринологии. Термин "пустое" турецкое седло (ПТС) предложен в 1951 году W. Busch; Клинические симптомы, ассоциированные с "пустым" седлом, впервые описал в 1968 г. N Guiot.

В норме ПТС заполнено ликвором, гипофизарной тканью; вход в турецкое седло прикрывает твердая мозговая оболочка - диафрагма седла. Благодаря применению неинвазивного метода магнитно-резонансной томографии (MRT) возможности изучения этой патологии значительно возросли. Установлено, что для формирования "пустого" турецкого седла необходимо два условия: недостаточность диафрагмы и внутричерепная гипертензия [1,2].

По патогенетическим механизмам ПТС разделяют на первичное и вторичное [3]. Первичный синдром ПТС обусловлен врожденным недоразвитием или отсутствием диафрагмы турецкого седла; при этом пролабирующий в полость седла ликвор сдавливает гипофиз, приводя к нарушению нейро-эндокринной регуляции и формированию комплекса неврологических, эндокринных и зрительных расстройств [4]. Остальные факторы, приводящие к уменьшению объёма гипофиза - первичная гипофункция периферических эндокринных желез, частые беременности, аборты, климакс, длительное применение гормонов, инфаркт гипофиза, некоторые аутоиммунные заболевания, лишь способствуют его развитию [5]. Вторичное ПТС образуется после хирургического, лучевого или комбинированного лечения заболеваний хиазмально-селлярной области [6].

*e-mail: simahuseynova@mail.ru
Первичное ПТС диагностируется преимущественно (75-80\%) у женщин в возрасте от 35 до 55лет, большинство которых страдает ожирением. Синдром ПТС выявляется также у 10\%-64\% больных с доброкачественной внутричерепной гипертензией [6,7]. Диагностика первичного ПТС основывается на данных визуализации хиазмально-селлярной области методом магнтно-резонансной томографии (MPТ), позволяющей проводить исследование в любой плоскости тонкими срезами 1-1.5 мм. При этом в полости турецкого седла выявляется наличие цереброспинальной жидкости; гипофиз уплотнен, деформирован, нередко имеет вид тонкого ободка, повторяющего контуры седла.Также наблюдается асимметричное пролабирование супраселлярной цистерны в полость седла, сопровождающееся смещением воронки, истончение и удлинение воронки гипофиза [9]. Наиболее типичные клинические симптомы первичного осложненного ПТС представлены сочетанием различных зрительных, неврологических и нейроэндокринных нарушений. Среди неврологических симптомов, обусловленных повышением внутричерепного давления, наиболее часто наблюдается головная боль (80-90\%), а также вегетативные синдромы и кризы, обусловленные патологией гипоталамуса и сопровождающиеся повышением артериального давления, кардиалгией, одышкой и др. $[10,12]$. Эндокринные симптомы, представленные гипофизарными нарушениями, аналогичны изменениям, наблюдаемым при аденоме гипофиза [11]. Нейроофтальмологические нарушения при первичном синдроме ПТС различны по характеру и степени выраженности. Зрительные расстройства представлены субъективными жалобами на зату- 
манивание зрения, диплопию, фотопсию и объективными признаками, указывающими на снижение зрения и изменение полей зрения, отек и атрофию зрительного нерва, глаукому $[11,13,14]$.

Цель работы: изучение нейроофтальмологических проявлений синдрома первичного ПТС.

Материал и методы. Обследовано 25 пациентов (19 женщин, 6 мужчин) с синдромом первичного ПТС в возрасте от 24 до55лет. Недостаточность диафрагмы турецкого седла (по данным МРТ) была диагностирована во всех случаях. Среди этиологических факторов, влияющих на развитие ПТС, по результатам МРТ также можно было отметить повышенное внутричерепное давления у 21 и наличие доброкачественной внутричерепной гипертензии - у 7 больных.

Больные обращались в Национальный центр офтальмологии им. академика 3.Алиевой с жалобами на зрительные расстройства (в сроки от 3 недель до 0,5-1,0 года от начала заболевания). Наряду с этим, почти во всех случаях пациенты предъявляли жалобы на почти постоянную головную боль различной степени, не имеющую определенной локализации; подъем артериального давления, боли в области сердца, одышку, обусловленные повышением внутричерепного давления и вегетативными нарушениями. Нередко выявлялись эндокринные расстройства (гипотериоз, аменорея), связанные с нарушением тропной функции гипофиза. Таким образом, жалобы больных были представлены комплексом офтальмологических, неврологических и эндокринных нарушений.

Офтальмологическое обследование включало визометрию, рефрактометрию, тонографию, автоматическую статическую периметрию, офтальмобиомикроскопию.

Результаты и обсуждение. Диагноз синдрома первичного ПТС был установлен на основании нейроофтальмологического статуса и данных МРТ; наряду с этим учитывались характерные неврологические жалобы, вегетативные и эндокринные нарушения.

Снижение остроты зрения различной сте- пени выраженности наблюдалось почти у всех больных с верифицированным первичным ПТС. Последнее возможно объяснялось обращением в клинику больных с уже имеющимися зрительными нарушениями. В 18 случаях пациенты жаловались на ретробульбарную боль, фотопсии, нечеткость зрения, диплопию, особенно при взгляде вблизь, что сопровождалось временным ослаблением конвергенции, связанным с активацией симпатической иннервации и ослаблением парасимпатического влияния [13]. Отек дисков зрительных нервов различной степени выраженности, обусловленный внутричерепной гипертензией диагностирован у 10 больных, из них в 8 случаях - двусторонний. У двух больных, наблюдалась вторичная атрофия зрительных нервов, вероятно как исход застойных дисков. В одном случае диагностирован тромбоз нижних ветвей центральной вены сетчатки с развитием макулярного отека (в литературе имеются единичные наблюдения окклюзии центральной вены сетчатки у больных с синдромом ПТС [15]. В основе изменений глазного дна (острая ишемия сетчатки и диска зрительного нерва, сдавление отечным диском проходящей в ней центральной вены сетчатки) лежат гемодинамические нарушения в бассейне внутренней сонной - глазничной артерий [16]. Изменение поля зрения было диагностировано у 13 больных: у 5 - концентрическое сужение различной степени выраженности, 4 - неполная битемпоральная гемианопсия, 3 - центральные и парацентральные скотомы и в 1случае - биназальная гемианопсия. В своих работах [15,17]. Самсонова Л.Н указывает на возможные причины развития изменений поля зрения у больных с первичным синдромом ПТС (повышенное внутричерепное давление, ишемия хиазмы, нарушение кровоснабжения латеральных отделов хиазмы, сдавление отечного нерва в узком оптическом канале, давление внутренней сонной артерии на внутреннюю часть зрительного нерва и др.).

Заключение. Синдром ПТС представляет собой симптомокомплекс, в основе которого лежат эндокринные, неврологические и зри- 
тельные нарушения. Этиологию и патогенез синдрома определяют врожденная недостаточность диафрагмы турецкого седла и внутричерепная гипертензия. Зрительные нарушения при первичном "пустом" турецком седле представляют собой серьезное осложнение. Своевременная диагностика и лечение боль- ных с синдромом ПТС позволит избежать значительного снижения зрительных функций.

Изучение офтальмологических аспектов синдрома ПТС представляет большой интерес, так как врачам нередко приходится сталкиваться со зрительными нарушениями, не обусловленными патологией самого глаза.

\title{
ЛИТЕРАТУРА
}

1. Бабарина Н.Б. Клинико-гормональные аспекты синдрома "пустого" турецкого седла. // Автореф. дис.канд.мед.наук. - М.,1999;

2. Bjerre P. The empty sella. A reappraisal of etiolojy and patogenesis //Acta Neurol.Scand.- 1990. -Vol.130. - P.1-25. 3. Bergland R.M., Ray B.S., Torak R.M. Anatomical variation in the hituitari gland and adjacent structures in 225 humanautopsicases //J/Neurosurj.-1968- Vol.28. - P.93-99. 4. Медведева А.А..Савостьянов Т.Г., Деникина О.Э. Синдром сдавления гипофиза в турецком седле, механизмы развития. //Арх. патологии.- 1997,3. - С.32-38. 5. Деев А.С. О "пустом" турецком седле при доброкачественной

6. внутричерепной гипертензии.// Журн. невропатологии и психиатрии им. С.С. Корсакова.-1991,10. - С.106108.

7. В.И. Морозов, А.А.Яковлев. Заболевания зрительного пути (клиника, диагностика, лечение). - С.494495. М.2010.

8. Елисеева М.Н.Ю., Серова Н.К.,Шифрин М.А. и др. Нейроофтальмологические аспекты синдрома доброкачественной внутричерепной гипетензии // Вест. офтальмол. - 2008. - № 3. - С.26-30.
9. Bjerre P., Lindholm J.Gildensted C. // Acta Neurol.Scand. - 1982. - Vol.66. P. 472-481.

10. Коновалов А.Н., Корниенко В.К., Пронин И.Н. Магнитно-резонансная томография в нейрохирургии. - М.,1997. - 1997. - C.470.

11. Вегетативные расстройства / Под ред. А.М.Вейна. М.: Мед.информ.агентство, 1998, - 749с.

12. Макаров А.Ю., Прохоров А.А., Сахарова Н.Ю., Евтюхина А.Н.// Журн.невропатол. и психиатр. - 2002. - №6. - C.22-26

13. Мизецкая Е.А., Снегирева Р.Я. Эндокринные нарушения при "пустом" турецком седле.

14. Нестеров А.П.Глаукома. - М; 1995.

15. Bjerre P. // Acta Neurol.Scand. - 1990. - Vol.130. - P 125.

16. Самсонова Л.Н. Офтальмологические эквиваленты синдрома первичного "пустого" турецкого седла / Вест. офтальмол. - 2006. - № 4. - С.41-43

16. Neuro - Ophthalmologiya / ED J.S.Glaser Philadelphia /1999

17. Самсонова Л.Н. Зрительные нарушения при синдроме "пустого" турецкого седла / Вест. офтальмол. 2003. - № 5. - C.52-53.

\section{XÜLASə}

\section{“BOŞ" TÜRK YӘHӘRİ SINDROMUNUN OFTALMOLOJİ ASPEKTLORİ}

\author{
${ }^{1}$ Hüseynova S.Q., ${ }^{2}$ Dünyamalıyev H.Q. \\ ${ }^{1}$ Akademik Zorifo Oliyeva adına Milli Oftalmologiya Morkəzi, Bakı; \\ ${ }^{2}$ Milli Onkologiya Morkəzi, Bakı
}

\begin{abstract}
Məqsəd. İlkin "boş" türk yəhəri (BTY) sindromunun neyrooftalmoloji təzahürlərinin öyrənilməsi.
Tədqiqatın material və metodları. BTY sindromu ilə 24-55 yaş arası 25 pasiyent (19 qadın, 6 kişi) müayinə olunmuşdur. Bütün hallarda MRT göstəricilərinə görə türk yəhərinin diafraqmasının çatışmazlı̆ı və yüksək kəllədaxili təzyiqi qeyd etmək olar. Oftalmoloji müayinə vizometriya, refraktometriya, tonoqrafiya, avtomatik statik perimetriya və oftalmobiomikroskopiyanı daxil edirdi.

Nəticələr və onların müzakirəsi. Təsdiq olunmuş ilkin BTY sindromu ilə xəstələrdə baş və retrobulbar ağrı, fotopsiya, qeyri-dəqiq görmə, konvergensiyanın pozulması, diplopiya, görmə itiliyinin pozulmaları, görmə sahəsinin dəyişiklikləri, görmə siniri disklərinin ödemi, ikincili atrofiyası, tor qişanın mərkəzi venasının trombozu müşahidə olunurdu.

Yekun. BTY sindromu endokrin, nevroloji və görmənin pozulmaları ilə şərtlənən simptomokompleksdir. Türk yəhərinin diafraqmasının anadangəlmə çatı̧̧mazlığı və kəllədaxili hipertenziya BTY sindromun etiologiyasını və patogenezini müəyyən edir.
\end{abstract}

Açar sözlər: "boş" türk yəhəri, kəllədaxili hipertenziya, görmənin pozulmaları. 


\title{
SUMMARY
}

\section{OPHTHALMIC ASPECTS OF THE "EMPTY" TURKISH SADDLE SYNDROME}

\author{
${ }^{1}$ Huseynova S.K., ${ }^{2}$ Dunyamaliyev Kh.K. \\ ${ }^{1}$ National Center of Ophthalmology named after acad. Zarifa Aliyeva, Baku \\ ${ }^{2}$ National Center of Oncology, Baku
}

The aim of the study is neuro-ophthalmologic aspects of the syndrome of primary "Empty" Turkish saddle syndrome. Material and methods. A total of 25 patients ( 19 women and 6 men) with the syndrome of primary "empty Turkish saddle" aged 24-55. Lack of diaphragm sella (according to MRI) has been diagnosed in all cases. Among the etiologic factors affecting the development of the "empty Turkish saddle" according to the results of MRI the increased intracranial pressure in 21 patients and the presence of benign intracranial hypertension in 7 patients could be also noted. Patients addressed to the National Center of Ophthalmology with complaints of visual disturbances (in a period of 3 weeks to 0.5-1.0 years from onset). In addition, in almost all cases, the patients complained of almost constant headache of varying degrees with no specific localization, rise in blood pressure, heart pain, shortness of breath caused by increased intracranial pressure and autonomic disturbances. Ophthalmologic examination included visometry, refractometery, tonography, automated static perimetry, and oftalmo-biomicroscopy.

While examining the papilledema of varying severity in 10 patients, 2 patients with secondary atrophy of the optic nerve, in 1 case the thrombosis of the central retinal vein. Change in the field of view was diagnosed in 13 patients: in 5 -concentric constriction of varying severity, in 4 - incomplete bitemporal hemianopsia, in 3 - central and paracentral scotoma and in 1 case - binasal hemianopsia.

Results. The syndrome of primary "empty Turkish saddle" syndrome is a syndrome, which is based on the endocrine, neurological and visual disturbances. The etiology and pathogenesis of congenital deficiency syndrome define diaphragm sella and intracranial hypertension. In the basis of the above-mentioned neuro-oftalmic changes there are an intracranial hypertension and hemodynamic abnormalities in the basin of the internal carotid and orbital arteries.

Conclusion. The research of the ophthalmic manifestations of the "empty" Turkish saddle syndrome arise big interest for the ophthalmologists in cases of the visual impairment which are not caused by ophthalmic pathology.

Key words: "Empty" sella, intracranial hypertension, visual impairment. 